\title{
Survival of Clinical and Food Isolates of Listeria monocytogenes Through Simulated Gastrointestinal Tract Conditions
}

\author{
Rosário Ramalheira, ${ }^{1}$ Marta Almeida, ${ }^{2}$ Joana Azeredo, ${ }^{2}$ Teresa R.S. Brandão, \\ Gonçalo Almeida, Joana Silva, and Paula Teixeira ${ }^{1}$
}

\begin{abstract}
Twenty-seven strains of Listeria monocytogenes previously isolated from food $(n=16)$ and human patients of listeriosis $(n=11)$ were characterized and compared based on their ability to survive through the simulated gastrointestinal tract conditions. Cells were exposed $(60$ or $120 \mathrm{~min}$ ) to low $\mathrm{pH}$ in the presence of pepsin, to simulate the digestion in the stomach, and subsequently to bile salts to simulate the digestion in the small intestine (60 or $120 \mathrm{~min}$ ). Their survival was shown to be origin- (food and clinical) and strain dependent $(p<0.001)$ and also significantly dependent on the imposed simulated gastric conditions (long vs. quick exposure) $(p<0.001)$. In comparison to the food isolates, the clinical strains were in general more resistant and survived better to the two challenges imposed. Some of the tested strains, after the exposure to low $\mathrm{pH}$ in the presence of pepsin, became injured and subsequently more susceptible to the bile salts challenge. It was demonstrated that one of the most important natural barriers against foodborne pathogens might not be effective since it was shown that L. monocytogenes isolates that survived through the $\mathrm{pH}$ challenge were also able to survive the subsequent challenge to bile salts.
\end{abstract}

\section{Introduction}

$\mathbf{F}$ RSt Recognized by MurRay et aL. (1926) Listeria monocytogenes is a pathogen often present in a variety of readyto-eat foods, such as smoked fish, soft cheeses, fermented sausages, and lightly heat-treated meat products. There are also indications of their growth on food production lines and in the food processing environment, especially in zones of difficult access during normal cleaning and disinfection procedures (Nørrung, 2000). This pathogen has the ability to survive and grow under a wide range of environmental conditions, such as the presence or absence of air, refrigeration temperatures $\left(0-4{ }^{\circ} \mathrm{C}\right)$, high salt concentrations, water activities above 0.92, and at pH values between 4.3 and 9.6 (Ribeiro et al., 2006).

L. monocytogenes have been responsible for outbreaks and sporadic cases of listeriosis, a severe infection particularly among certain groups within the general population, namely immunocompromised persons (e.g., organ transplant or cancer patients), HIV-infected individuals, pregnant women, newborn babies, and the elderly (Bell and Kyriakides, 2005;
Almeida et al., 2006). Although the infection occurs infrequently, the fatality rate is high (Almeida et al., 2006).

Ingestion of contaminated foods is the main route of infection (McLauchlin, 1996; Brett et al., 1998; Soultos et al., 2007). Virulent strains of L. monocytogenes that survive the passage through the stomach, where the buffering capacity of some foods may protect the organisms further along the gastrointestinal (GI) tract (McLauchlin et al., 2004; Sleator et al., 2007), invade the GI epithelium and enter phagocytic host cells, where the bacteria are able to survive, multiply, and be carried in the blood to various organs (particularly the brain and/or uterus) (Nørrung, 2000). The infection via the GI tract presents a series of challenges by host defense mechanisms (Miller and Czuprynski, 2002). Understanding the complex interactions between pathogenic microorganism and the host organism's GI tract is still necessary.

The aim of the present work was to characterize and compare 27 L. monocytogenes strains, from food and from clinical cases of listeriosis that have occurred in Portugal, representing several serotypes, based on their capacity to survive through

\footnotetext{
${ }^{1} \mathrm{CBQF} /$ Biotechnology School, Portuguese Catholic University, Oporto, Portugal.
}

${ }^{2}$ Biological Engineering Department, University of Minho, Braga, Portugal. 
simulated GI tract conditions and to evaluate the possibility of cellular damage through this challenge.

\section{Materials and Methods}

\section{Microbial strains}

The isolates of L. monocytogenes that were used during this study are listed in Table 1. All the isolates were obtained from the Escola Superior de Biotecnologia culture collection (Porto, Portugal) and were selected based on their origin (clinical and food), serogroup $(1 / 2 b, 1 / 2 a, 1 / 2 c$, and $4 b)$, and resistance profile to heavy metals (arsenic, cadmium, and tetracycline). Clinical isolates collected from human patients of listeriosis that occurred in Portugal were kindly supplied by several Portuguese health institutions.

\section{Preparation of the inoculum}

Stock cultures were stored in cryotubes at $-80^{\circ} \mathrm{C}$ in tryptic soy broth with $6 \mathrm{~g} / \mathrm{L}$ yeast extract (TSBYE; Pronadisa, Madrid, Spain), with $30 \%$ (v/v) of glycerol. From the cryotube, an aliquot of L. monocytogenes was streaked on tryptic soy agar with $6 \mathrm{~g} / \mathrm{L}$ yeast extract (TSAYE) and incubated at $37^{\circ} \mathrm{C}$ during $24 \mathrm{~h}$. To prepare each preinoculum, a pure colony of each isolate was transferred to $10 \mathrm{~mL}$ of TSBYE followed by incubation at $37^{\circ} \mathrm{C}$ for $24 \mathrm{~h}$. This culture was then subsequently diluted 1:100 in TSBYE and incubated at $37^{\circ} \mathrm{C}$ for $24 \mathrm{~h}$ to yield cells in the stationary phase of growth. After centrifugation (7000 g, $10 \mathrm{~min}, 4^{\circ} \mathrm{C}$; Rotina 35; Hettich Zentrigugen, Oxford, $\mathrm{CT})$, the pellet was resuspended to the original volume with sterile Ringer's solution (LAB M, Bury, United Kingdom).

\section{Gl conditions}

The simulation of the gastric juice conditions was performed according to Madureira et al. (2005) in buffered peptone water (BPW; LabM, Bury, UK) adjusted to $\mathrm{pH}$ 2.5-3.0 $(\mathrm{HCl}, 1 \mathrm{M})$ with $1000 \mathrm{U} / \mathrm{mL}$ of a filter sterilized solution of pepsin (Sigma, Madrid, Spain). After $60 \mathrm{~min}$ (to simulate a quick gastric transit) or $120 \mathrm{~min}$ (to simulate a slow gastric transit), the simulation of the effect of bile salts in the small intestine was performed by the addition of bile salts until a final concentration of $0.3 \%(\mathrm{w} / \mathrm{v}$ ) (Pronadisa) followed by $\mathrm{pH}$ readjustment to 7 with sodium hydroxide. Cells were exposed to bile salts for 60 or $120 \mathrm{~min}$ (quick and slow digestion, respectively) (Madureira et al., 2005).

Three independent controls were used: $\mathrm{BPW}$ at $\mathrm{pH}$ 7, BPW containing $0.3 \%(\mathrm{w} / \mathrm{v})$ bile salts at $\mathrm{pH} 7$, and $\mathrm{BPW}$ containing pepsin $(1000 \mathrm{U} / \mathrm{mL})$ at $\mathrm{pH} 7$ (Madureira et al., 2005). The solutions simulating each condition or controls were inoculated with $1 \%(\mathrm{v} / \mathrm{v})$ of bacterial inoculum prepared as described above. Samples were taken at $30 \mathrm{~min}$ intervals, and enumeration was performed as described below. For each bacterial strain, all assays were performed in triplicate.

Table 1. Microbial Strains Selected for the Study and Their Characterization According to the Serogroup and Resistance to Arsenic, Cadmium, and Tetracycline

\begin{tabular}{|c|c|c|c|c|c|}
\hline \multirow[b]{2}{*}{ Listeria monocytogenes strain } & \multirow[b]{2}{*}{ Source } & \multirow[b]{2}{*}{ Serogroup } & \multicolumn{3}{|c|}{ Resistance to ${ }^{\mathrm{a}}$} \\
\hline & & & Arsenic & Cadmium & Tetracycline \\
\hline L. monocytogenes_747 & Food & $1 / 2 b$ & $\mathrm{~S}$ & $\mathrm{R}$ & $\mathrm{S}$ \\
\hline L. monocytogenes_925 & Food & $1 / 2 b$ & S & $\mathrm{R}$ & S \\
\hline L. monocytogenes_930 & Food & $1 / 2 \mathrm{a}$ & S & $\mathrm{R}$ & $\mathrm{S}$ \\
\hline L. monocytogenes_903 & Food & $4 b$ & $\mathrm{R}$ & $S$ & $S$ \\
\hline L. monocytogenes_1044 & Food & $4 \mathrm{~b}$ & $\mathrm{R}$ & S & S \\
\hline L. monocytogenes_842 & Food & $1 / 2 \mathrm{c}$ & $S$ & $\mathrm{R}$ & S \\
\hline L. monocytogenes_854 & Food & $4 b$ & $S$ & $\mathrm{R}$ & $S$ \\
\hline L. monocytogenes_1216 & Food & $1 / 2 b$ & $S$ & $\mathrm{R}$ & S \\
\hline L. monocytogenes_1305 & Food & $1 / 2 c$ & $\mathrm{R}$ & $S$ & $\mathrm{~S}$ \\
\hline L. monocytogenes_994 & Food & $1 / 2 \mathrm{a}$ & $\mathrm{S}$ & $\mathrm{R}$ & $\mathrm{S}$ \\
\hline FSL-F7-001 & Food & $1 / 2 c$ & $\mathrm{R}$ & $\mathrm{R}$ & $\mathrm{R}$ \\
\hline FSL-F7-010 & Food & $1 / 2 a$ & $S$ & $\mathrm{R}$ & $\mathrm{S}$ \\
\hline FSL-F7-020 & Food & $1 / 2 \mathrm{a}$ & $S$ & S & $\mathrm{S}$ \\
\hline FSL-F7-088 & Food & $1 / 2 c$ & $S$ & $\mathrm{R}$ & S \\
\hline FSL-F7-099 & Food & $4 b$ & $\mathrm{R}$ & $S$ & S \\
\hline FSL-F7-128 & Food & $1 / 2 b$ & S & $\mathrm{R}$ & S \\
\hline L. monocytogenes_1761 & Clinic & $1 / 2 a$ & $\mathrm{~S}$ & $\mathrm{R}$ & S \\
\hline L. monocytogenes_2065 & Clinic & $1 / 2 b$ & $\mathrm{~S}$ & $\mathrm{R}$ & $\mathrm{S}$ \\
\hline L. monocytogenes_2074 & Clinic & $4 b$ & $S$ & $S$ & $S$ \\
\hline L. monocytogenes_2092 & Clinic & $4 b$ & $\mathrm{R}$ & $S$ & S \\
\hline L. monocytogenes_2086 & Clinic & $1 / 2 \mathrm{a}$ & $S$ & $S$ & S \\
\hline L. monocytogenes_1000 & Clinic & $4 b$ & $S$ & $S$ & $S$ \\
\hline L. monocytogenes_1001 & Clinic & $4 b$ & $S$ & $\mathrm{R}$ & $\mathrm{S}$ \\
\hline L. monocytogenes_1547 & Clinic & $1 / 2 b$ & $S$ & $S$ & $\mathrm{~S}$ \\
\hline L. monocytogenes_1891 & Clinic & $1 / 2 \mathrm{a}$ & $S$ & $S$ & $S$ \\
\hline L. monocytogenes_1562 & Clinic & $1 / 2 b$ & $\mathrm{~S}$ & $\mathrm{R}$ & $\mathrm{S}$ \\
\hline L. monocytogenes_2103 & Clinic & $1 / 2 a$ & S & $\mathrm{R}$ & $S$ \\
\hline
\end{tabular}

${ }^{a}$ Growth ( $R$, resistant) or no growth (S, susceptible) onto three isosensitest agar plates (Oxoid, Basingstoke, United Kingdom) containing $500 \mu \mathrm{g} / \mathrm{mL}$ sodium arsenite, $75 \mu \mathrm{g} / \mathrm{mL}$ cadmium chloride monohydrate, and $8 \mu \mathrm{g} / \mathrm{mL}$ of tetracycline-hydrochloride. 


\section{Enumeration}

Enumeration of the survivors was performed by plating appropriate dilutions prepared in Ringer's solution (in duplicate) on TSAYE and on Palcam agar (Merck, Darmstadt, Germany) plus selective supplement (Merck), by the drop count technique (Miles and Misra, 1938). TSAYE medium is nonselective and was used to enumerate both injured and noninjured cells. Palcam agar is selective for L. monocytogenes and was used for enumeration of noninjured cells. Colonies were enumerated after incubation at $37^{\circ} \mathrm{C}$ for $48 \mathrm{~h}$.

\section{Statistical analysis}

As mentioned above, all the experiments were repeated at least three times. A one-way analysis of variance (ANOVA) was performed to test significant effects of the following: (i) slow and quick digestion, (ii) enumeration media (Palcam and TSAYE), and (iii) origin and strain on the survival of the L. monocytogenes through the tested conditions. Two-way ANOVA was also performed for concluding about strain/ media and type of digestion/strain effects.
All calculations were carried out using the software KaleidaGraph (version 4.04; Synergy Software, Reading, PA).

\section{Results}

The survival of cells to the simulated GI conditions is illustrated in Tables 2 and 3. The resistance to both quick and slow digestions was shown to be dependent on the origin, strain, and simulated GI conditions $(p<0.001)$. Clinical isolates were significantly $(p<0.001)$ more resistant than food isolates (Tables 2 and 3); 2.7 and $3.6 \mathrm{log}$ reductions (mean values) in viable counts were observed during the simulated slow GI transit of clinical and food strains, respectively. A similar tendency was observed during the simulated quick transit; 1.8 and $3.0 \log$ reductions for clinical and food isolates, respectively.

None of the strains demonstrated sensitivity to pepsin (at neutral $\mathrm{pH}$ ) or to bile salts challenge alone (control cells, data not shown).

Survival of L. monocytogenes after the exposure to the drop of $\mathrm{pH}$ in the presence of pepsin and subsequent challenge to

Table 2. Survival of Clinical and Food Isolates of Listeria monocytogenes Through Slow Digestion When Enumeration Was Performed in Selective (Palcam) and Nonselective (Tryptic Soy Agar with 6 g/L Yeast Extract) Media

\begin{tabular}{|c|c|c|c|c|c|c|}
\hline \multirow[b]{3}{*}{ Plating media } & \multirow[b]{3}{*}{ Source } & \multicolumn{5}{|c|}{$\log c f u / m L^{\mathrm{a}}$} \\
\hline & & \multirow{2}{*}{$\frac{0 \text { min }^{\mathrm{b}}}{\text { TSAYE }}$} & \multicolumn{2}{|c|}{$120 \min ^{\mathrm{c}, \mathrm{d}}$} & \multicolumn{2}{|c|}{$240 \min ^{\mathrm{c}, \mathrm{e}}$} \\
\hline & & & Palcam & TSAYE & Palcam & TSAYE \\
\hline L. monocytogenes_1547 & Clinical & $7.1 \pm 0.0$ & $4.8 \pm 0.1$ & $5.0 \pm 0.1$ & $5.3 \pm 0.0$ & $5.7 \pm 0.0$ \\
\hline L. monocytogenes_1761 & Clinical & $7.2 \pm 0.1$ & $6.0 \pm 0.0$ & $6.5 \pm 0.1$ & $5.0 \pm 0.0$ & $5.1 \pm 0.1$ \\
\hline L. monocytogenes_1891 & Clinical & $7.3 \pm 0.1$ & $4.9 \pm 0.0$ & $5.1 \pm 0.1$ & $4.1 \pm 0.0$ & $4.1 \pm 0.0$ \\
\hline L. monocytogenes_2065 & Clinical & $7.0 \pm 0.0$ & $4.8 \pm 0.0$ & $5.1 \pm 0.1$ & $2.6 \pm 0.7$ & $2.8 \pm 0.5$ \\
\hline L. monocytogenes_2086 & Clinical & $7.3 \pm 0.0$ & $4.0 \pm 0.1$ & $4.1 \pm 0.1$ & $4.2 \pm 0.1$ & $4.2 \pm 0.0$ \\
\hline L. monocytogenes_2092 & Clinical & $7.1 \pm 0.0$ & $4.0 \pm 0.0$ & $4.1 \pm 0.1$ & $3.2 \pm 0.1$ & $3.5 \pm 0.6$ \\
\hline L. monocytogenes_2103 & Clinical & $7.5 \pm 0.0$ & $5.9 \pm 0.1$ & $6.4 \pm 0.2$ & $6.0 \pm 0.2$ & $6.1 \pm 0.1$ \\
\hline L. monocytogenes_2074 & Clinical & $7.3 \pm 0.0$ & $6.2 \pm 0.0$ & $6.3 \pm 0.1$ & $6.1 \pm 0.0$ & $6.1 \pm 0.0$ \\
\hline L. monocytogenes_1000 & Clinical & $6.9 \pm 0.1$ & $4.4 \pm 0.1$ & $4.5 \pm 0.2$ & $4.1 \pm 0.1$ & $4.7 \pm 0.1$ \\
\hline L. monocytogenes_1001 & Clinical & $6.7 \pm 0.1$ & $3.5 \pm 0.1$ & $3.8 \pm 0.2$ & $<1.8 \pm 0.0$ & $<1.8 \pm 0.0$ \\
\hline L. monocytogenes_1562 & Clinical & $6.7 \pm 0.0$ & $4.5 \pm 0.2$ & $4.4 \pm 0.8$ & $4.6 \pm 0.9$ & $4.8 \pm 0.1$ \\
\hline L. monocytogenes_903 & Food & $7.1 \pm 0.0$ & $3.1 \pm 0.1$ & $4.3 \pm 0.3$ & $2.6 \pm 0.5$ & $2.8 \pm 0.3$ \\
\hline L. monocytogenes_1216 & Food & $6.9 \pm 0.0$ & $4.0 \pm 0.4$ & $4.8 \pm 0.1$ & $2.5 \pm 0.1$ & $2.7 \pm 0.0$ \\
\hline L. monocytogenes_1305 & Food & $7.3 \pm 0.1$ & $5.0 \pm 0.1$ & $5.4 \pm 0.2$ & $4.0 \pm 0.1$ & $4.4 \pm 0.5$ \\
\hline L. monocytogenes_747 & Food & $6.5 \pm 0.0$ & $<1.8 \pm 0.0$ & $<1.8 \pm 0.0$ & $<1.8 \pm 0.0$ & $<1.8 \pm 0.0$ \\
\hline L. monocytogenes_925 & Food & $6.7 \pm 0.2$ & $2.3 \pm 0.1$ & $2.7 \pm 0.4$ & $<1.8 \pm 0.0$ & $<1.8 \pm 0.0$ \\
\hline L. monocytogenes_930 & Food & $6.8 \pm 0.3$ & $<1.8 \pm 0.0$ & $<1.8 \pm 0.0$ & $<1.8 \pm 0.0$ & $<1.8 \pm 0.0$ \\
\hline L. monocytogenes_994 & Food & $6.7 \pm 0.3$ & $<1.8 \pm 0.0$ & $2.2 \pm 0.1$ & $<1.8 \pm 0.0$ & $<1.8 \pm 0.0$ \\
\hline L. monocytogenes_842 & Food & $7.1 \pm 0.0$ & $5.2 \pm 0.1$ & $5.5 \pm 0.6$ & $4.0 \pm 0.0$ & $4.1 \pm 0.1$ \\
\hline L. monocytogenes_854 & Food & $7.1 \pm 0.0$ & $3.7 \pm 0.2$ & $4.2 \pm 0.1$ & $2.3 \pm 0.3$ & $2.6 \pm 0.2$ \\
\hline L. monocytogenes_1044 & Food & $6.9 \pm 0.1$ & $3.7 \pm 0.5$ & $3.9 \pm 0.1$ & $2.2 \pm 0.6$ & $2.5 \pm 0.4$ \\
\hline FSL-F7-001 & Food & $6.9 \pm 0.1$ & $4.9 \pm 0.0$ & $4.9 \pm 0.1$ & $3.2 \pm 0.0$ & $3.7 \pm 0.0$ \\
\hline FSL-F7-010 & Food & $6.8 \pm 0.2$ & $5.9 \pm 0.3$ & $6.1 \pm 0.2$ & $5.2 \pm 0.0$ & $6.0 \pm 0.0$ \\
\hline FSL-F7-020 & Food & $6.8 \pm 0.1$ & $4.9 \pm 0.0$ & $5.0 \pm 0.1$ & $4.0 \pm 0.1$ & $4.2 \pm 0.9$ \\
\hline FSL-F7-088 & Food & $6.3 \pm 0.1$ & $5.8 \pm 0.2$ & $5.9 \pm 0.2$ & $4.7 \pm 0.4$ & $4.9 \pm 0.1$ \\
\hline FSL-F7-099 & Food & $6.4 \pm 0.1$ & $3.8 \pm 0.3$ & $4.0 \pm 0.0$ & $3.1 \pm 0.1$ & $3.9 \pm 0.0$ \\
\hline FSL-F7-128 & Food & $7.0 \pm 0.0$ & $1.9 \pm 0.2$ & $2.0 \pm 0.4$ & $2.1 \pm 0.0$ & $2.1 \pm 0.0$ \\
\hline
\end{tabular}

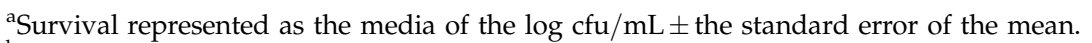

${ }^{\mathrm{b}}$ Initial counts obtained in Palcam (time 0; data not shown) and TSAYE were not significantly different $(p>0.05)$.

${ }^{\mathrm{c} C o u n t s}$ obtained in Palcam and TSAYE were significantly different $(p<0.001)$.

${ }^{\mathrm{d}}$ Survival after exposure at $\mathrm{pH} 2.5$ in the presence of pepsin.

eSurvival after exposure to $\mathrm{pH} 2.5$ in the presence of pepsin and subsequent exposure to bile salts at $\mathrm{pH} 7$.

TSAYE, tryptic soy agar with $6 \mathrm{~g} / \mathrm{L}$ yeast extract. 
Table 3. Survival of Clinical and Food Isolates of Listeria monocytogenes Through Quick Digestion When Enumeration Was Performed in Nonselective (TSAYE) Medium

\begin{tabular}{|c|c|c|c|c|}
\hline & \multirow[b]{2}{*}{ Source } & \multicolumn{3}{|c|}{$\log c f u / m L^{\mathrm{a}}$} \\
\hline & & $0 \mathrm{~min}$ & $60 \min ^{\mathrm{b}}$ & $120 \min ^{\mathrm{c}}$ \\
\hline L. monocytogenes_1547 & Clinical & $7.1 \pm 0.0$ & $6.2 \pm 0.1$ & $6.4 \pm 0.0$ \\
\hline L. monocytogenes_1761 & Clinical & $7.2 \pm 0.1$ & $6.1 \pm 0.0$ & $5.4 \pm 0.5$ \\
\hline L. monocytogenes_1891 & Clinical & $7.3 \pm 0.1$ & $6.1 \pm 0.1$ & $5.2 \pm 0.0$ \\
\hline L. monocytogenes_2065 & Clinical & $7.0 \pm 0.0$ & $5.5 \pm 0.1$ & $4.7 \pm 0.4$ \\
\hline L. monocytogenes_2086 & Clinical & $7.3 \pm 0.0$ & $5.2 \pm 0.0$ & $5.0 \pm 0.0$ \\
\hline L. monocytogenes_2092 & Clinical & $7.1 \pm 0.0$ & $7.5 \pm 0.0$ & $4.9 \pm 0.0$ \\
\hline L. monocytogenes_2103 & Clinical & $7.5 \pm 0.0$ & $6.3 \pm 0.0$ & $6.3 \pm 0.0$ \\
\hline L. monocytogenes_2074 & Clinical & $7.3 \pm 0.0$ & $6.6 \pm 0.0$ & $6.5 \pm 0.0$ \\
\hline L. monocytogenes_1000 & Clinical & $6.9 \pm 0.1$ & $4.7 \pm 0.1$ & $4.9 \pm 0.1$ \\
\hline L. monocytogenes_1001 & Clinical & $6.7 \pm 0.1$ & $3.9 \pm 0.1$ & $4.2 \pm 0.1$ \\
\hline L. monocytogenes_1562 & Clinical & $6.7 \pm 0.0$ & $4.7 \pm 0.0$ & $4.4 \pm 0.1$ \\
\hline L. monocytogenes_903 & Food & $7.1 \pm 0.0$ & $5.1 \pm 0.1$ & $2.7 \pm 0.3$ \\
\hline L. monocytogenes_1216 & Food & $6.9 \pm 0.0$ & $5.2 \pm 0.1$ & $3.9 \pm 0.2$ \\
\hline L. monocytogenes_1305 & Food & $7.3 \pm 0.1$ & $6.5 \pm 0.1$ & $5.6 \pm 0.1$ \\
\hline L. monocytogenes_747 & Food & $6.5 \pm 0.0$ & $1.4 \pm 1.9$ & $3.6 \pm 0.1$ \\
\hline L. monocytogenes_925 & Food & $6.7 \pm 0.2$ & $3.2 \pm 0.2$ & $<1.8 \pm 0.0$ \\
\hline L. monocytogenes_930 & Food & $6.8 \pm 0.3$ & $2.5 \pm 0.2$ & $2.7 \pm 0.0$ \\
\hline L. monocytogenes_994 & Food & $6.7 \pm 0.3$ & $4.3 \pm 0.3$ & $4.0 \pm 0.1$ \\
\hline L. monocytogenes_842 & Food & $7.1 \pm 0.0$ & $6.2 \pm 0.0$ & $2.3 \pm 0.6$ \\
\hline L. monocytogenes_854 & Food & $7.1 \pm 0.0$ & $4.9 \pm 0.1$ & $3.1 \pm 0.1$ \\
\hline L. monocytogenes_1044 & Food & $6.9 \pm 0.1$ & $5.3 \pm 0.0$ & $3.1 \pm 0.1$ \\
\hline FSL-F7-001 & Food & $6.9 \pm 0.1$ & $6.0 \pm 0.0$ & $4.9 \pm 0.2$ \\
\hline FSL-F7-010 & Food & $6.8 \pm 0.2$ & $6.1 \pm 0.0$ & $6.0 \pm 0.0$ \\
\hline FSL-F7-020 & Food & $6.8 \pm 0.1$ & $5.5 \pm 0.0$ & $5.7 \pm 0.1$ \\
\hline FSL-F7-088 & Food & $6.3 \pm 0.1$ & $4.1 \pm 0.0$ & $4.8 \pm 0.1$ \\
\hline FSL-F7-099 & Food & $6.4 \pm 0.1$ & $4.9 \pm 0.1$ & $3.9 \pm 0.1$ \\
\hline FSL-F7-128 & Food & $7.0 \pm 0.0$ & $3.0 \pm 0.0$ & $3.1 \pm 0.0$ \\
\hline
\end{tabular}

${ }^{a}$ Survival represented as the media of the $\log \mathrm{cfu} / \mathrm{mL} \pm$ the standard error of the mean.

${ }^{\mathrm{b}}$ Survival after exposure at $\mathrm{pH} 2.5$ in the presence of pepsin.

'Survival after exposure to $\mathrm{pH} 2.5$ in the presence of pepsin and subsequent exposure to bile salts at $\mathrm{pH} 7$.

bile salts is presented in Fig. 1 (simulated quick digestion) and Fig. 2 (simulated slow digestion).

With reference to the results obtained for the slow digestion, food strain FSL-F7-088 was the most resistant to the drop in $\mathrm{pH}$ in the presence of pepsin with approximately $40 \%$ survivors (Fig. 2A). However, all the other tested food and clinical strains were demonstrated to be very susceptible showing a survival of $17 \%$ (strain 2074) or lower (Fig. 2). This high susceptibility was also observed for the quick digestion (Fig. 1). In general, clinical isolates were significantly $(p<0.001)$ more resistant to an exposure to low $\mathrm{pH}$ plus pepsin than food isolates for both quick (Fig. 1) and long exposures (Fig. 2). Cell survived better $(p<0.001)$ exposure to bile salts than to acid in the presence of pepsin (Figs. 1 and 2). For both quick and long exposures to bile salts, after-exposure to low $\mathrm{pH}$ and pepsin survival was dependent on the strain being investigated $(p<0.001)$ but not on its origin $(p>0.05)$.

Concerning the simulated stomach conditions, for clinical and food strains, a higher survival was observed in the quick transit than in the long exposure $(p<0.001)$. The magnitude of this behavior varied significantly $(p<0.001)$ according to the tested strain (Figs. 1 and 2). With regard to survival of the double challenge (acid and pepsin and then bile salts), clinical strains survived better than food strains $(p<0.001)$ for both simulations (slow and quick transit). In relation to the enu- meration of L. monocytogenes, significant differences between the two plating media after the long digestion period were verified $(p<0.001)$. In general, and based on ANOVA results, the survivor counts were higher in the nonselective medium (TSAYE) than in the selective medium (Palcam; Table 2; $p<0.001)$. However, during the quick digestion, for food and clinical isolates, no significant differences $(p>0.05)$ were observed between the cellular counts on TSAYE and on Palcam agar media (data not shown).

\section{Discussion}

The survival of L. monocytogenes to the main stresses encountered during passage through the GI tract, that is, low $\mathrm{pH}$ in the present of pepsin and subsequent exposure to bile salts, was investigated. No cellular reduction was observed in the presence of pepsin or bile salts, alone (controls). Begley et al. (2002) and Olier et al. (2004) have previously reported a similar resistance to bile salts. However, King et al. (2003) reported that bile salts might have a deleterious effect on L. monocytogenes. Resistance to bile salts stresses has been demonstrated to be strain dependent (Begley et al., 2002; King et al., 2003; Olier et al., 2004). It is also important to point out that in the present study and in the studies by Begley et al. (2002) and Olier et al. (2004), survival of L. monocytogenes to 

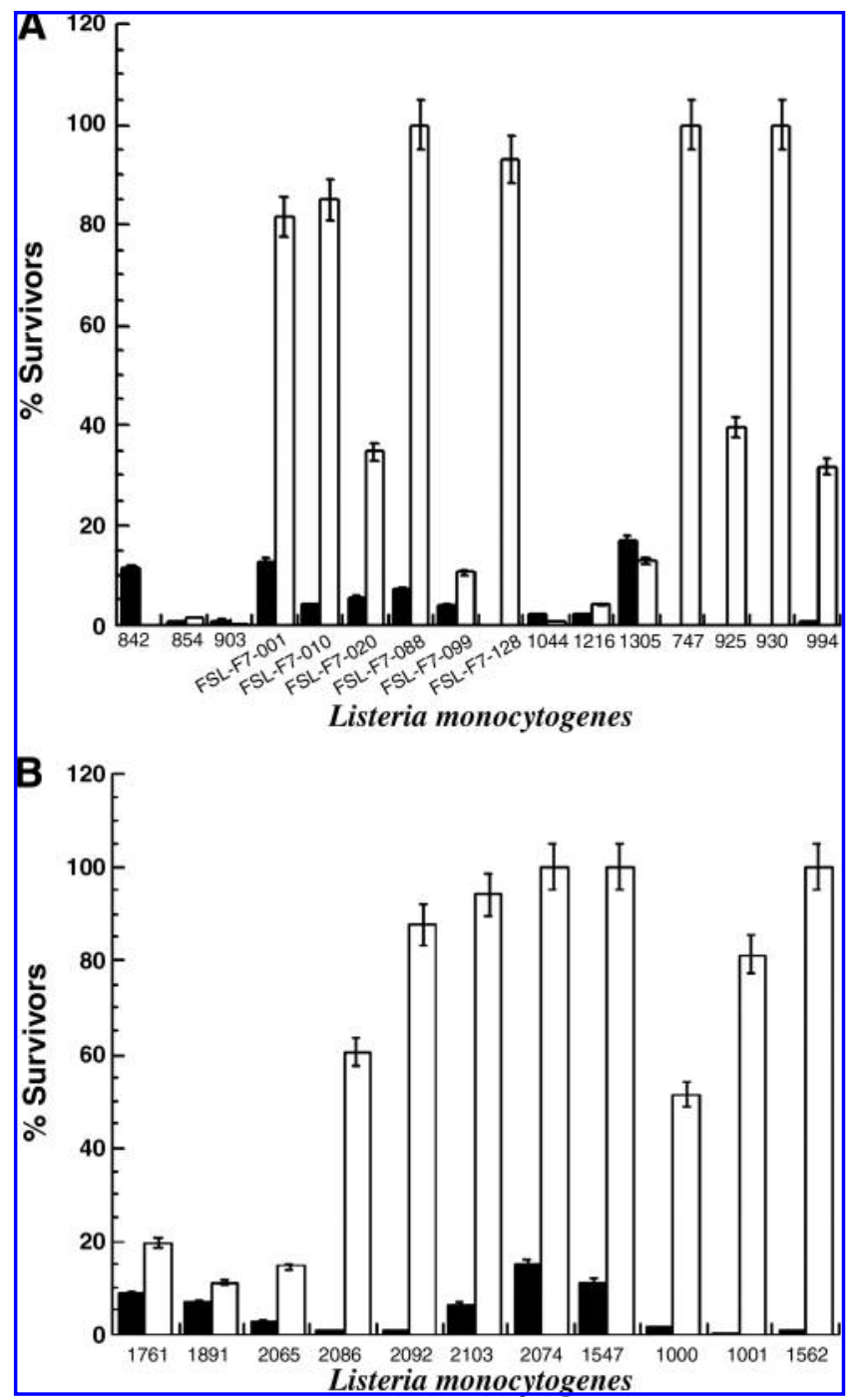

FIG. 1. Survival (\%) of food (A) and clinical (B) isolates of Listeria monocytogenes through the simulated quick digestion.

$\square$, After the exposure to the drop of $\mathrm{pH}$ in the presence of pepsin (expressed as \% of the initial counts) and $\square$, subsequent challenge to bile salts (expressed as $\%$ of the survivors to the previous condition).

bile salts was evaluated in nutritious media, BPW, and brainheart infusion, respectively, whereas King et al. (2003) evaluated resistance to bile salts in phosphate buffer. It is well known that the bacterial resistance to a particular stress varies according to the media where it is applied being higher, for most of the situations, in more nutritious media.

For the strains investigated, a lower survival was observed in the simulated stomach conditions than in the presence of bile salts. Using a dynamic model of the stomach and small intestine, Barmpalia-Davis et al. (2008a, 2009) also reported more drastic reductions in listerial populations during the gastric challenge than those observed in the simulated intestinal conditions.

Differences between counts on Palcam and TSAYE have already been described by Miller et al. (2006); these authors reported that on the selective medium, heat-injured Listeria innocua cells suffer additional stresses and might fail to repair,

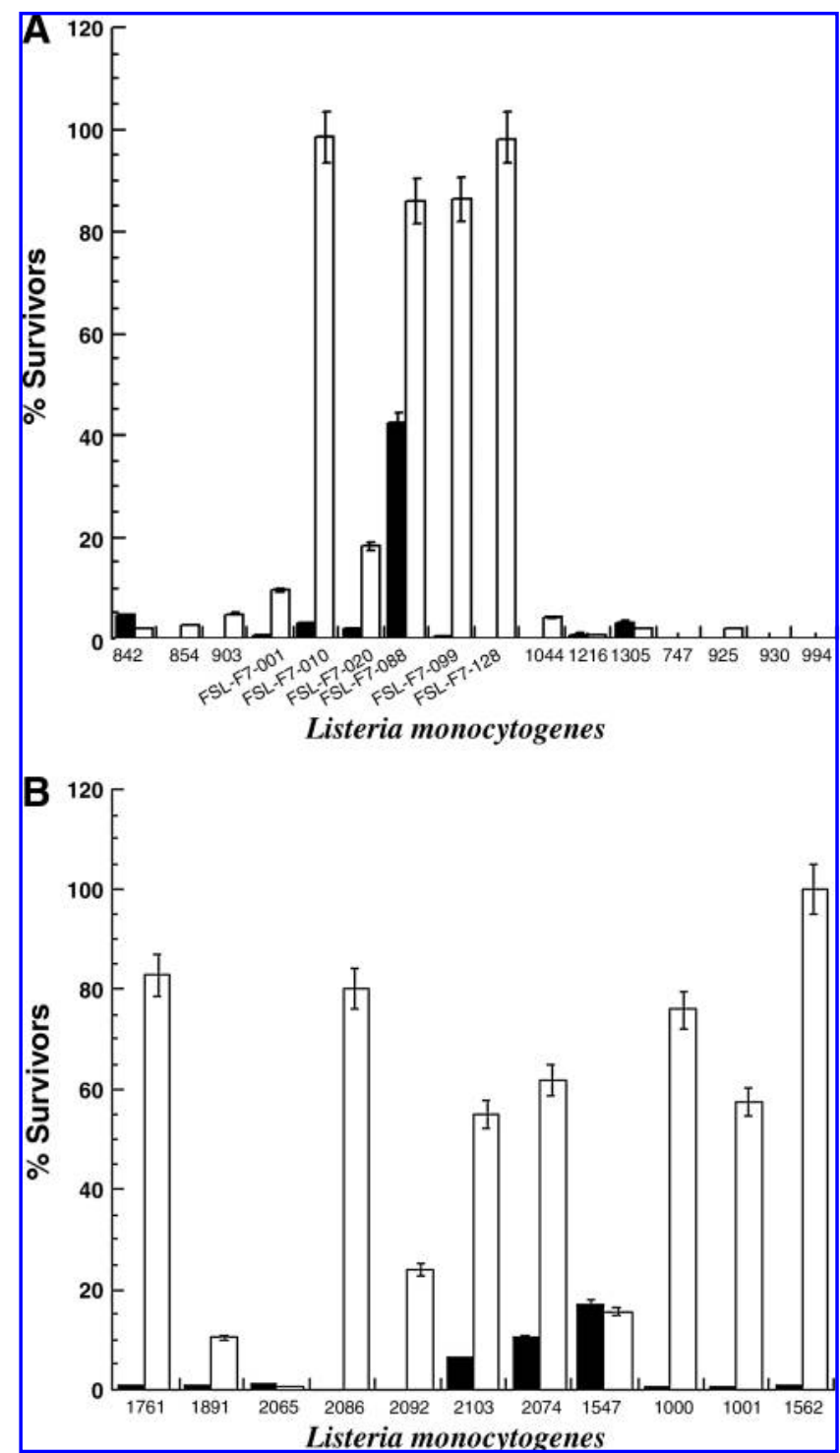

FIG. 2. Survival (\%) of food (A) and clinical (B) isolates of Listeria monocytogenes through the simulated slow digestion. 口. After the exposure to the drop of $\mathrm{pH}$ in the presence of pepsin (expressed as \% of the initial counts) and $\square$, subsequent challenge to bile salts (expressed as \% of the survivors to the previous condition).

becoming functionally inactive. Therefore, the differences in the viable cell counts between the two enumeration media suggest cellular damage, probably in the cytoplasmatic membrane (Nyachuba and Donnelly, 2005; Miller et al., 2006; Uyttendaele et al., 2008). This was concurrent with the results obtained in the present study for the survival through the slow digestion and with those presented by Barmpalia-Davis et al. (2009) related to the survival of L. monocytogenes to 120 min gastric exposure. Damage to the lipopolysaccharide of the outer membrane and denaturation of cytoplasmic proteins has been attributed to acid exposure (Brown and Booth, 1991). This may explain the lower counts in Palcam than in TSAYE and the increased susceptibility to bile salts following exposure to low $\mathrm{pH}$ in the presence of pepsin observed for most of the strains. Barmpalia-Davis et al. (2008a) 
obtained similar counts of L. monocytogenes on TSA and TSAYE throughout a gastric challenge. The reasons for this observation were not clear, but traits of individual strains and potential acid adaptation were proposed as possible explanations for these findings.

The capacity of L. monocytogenes to colonize the GI tract (Mahoney and Henriksson, 2003; Gahan and Hill, 2005; Sleator et al., 2007), to resist acidic conditions (Dykes and Moorhead, 2000; King et al., 2003; Vialette et al., 2003; Lianou et al., 2006; Ribeiro et al., 2006; Barmpalia-Davis et al., 2008a), to survive in the presence of bile salts (Begley et al., 2002; King et al., 2003; Olier et al., 2004; Barmpalia-Davis et al., 2008a), and to persist in the presence of pepsin (Branen and Davidson, 2000) has already been described by several authors.

Comparison of survival patterns to stress conditions of clinical versus food isolates has been addressed in several publications (Avery and Buncic, 1997; Dykes and Moorhead, 2000; Vialette et al., 2003; Olier et al., 2004; Lianou et al., 2006; Barmpalia-Davis et al., 2008a; Werbrouck et al., 2008). Avery and Buncic (1997) evaluated the effect of long-term storage at $4^{\circ} \mathrm{C}$ on the pathogenicity and growth characteristics of 30 strains of L. monocytogenes (15 clinical and 15 meat isolates). Clinical isolates demonstrated a higher resistance to these unfavorable conditions than food strains, concerning to pathogenicity and lag-phase duration at body temperature. Dykes and Moorhead (2000) showed that of the 30 strains of L. monocytogenes investigated, 28 decreased less than 1 log cycle after exposure to $\mathrm{pH} 2.5$ for $2 \mathrm{~h}$. No significant differences in this reduction were detected between clinical or food (meat) strains. However, the remaining two strains, both of meat origin, were significantly reduced in numbers under similar stress conditions. Vialette et al. (2003) evaluated the response of L. monocytogenes (four clinical isolates associated to fish products and four isolates from seafood) to stress conditions, which can occur during food processing. Clinical strains displayed better adaptation to $\mathrm{pH}$ and osmotic stresses than seafood strains. Olier et al. (2004) reported that independently of the origin (human, food, or food processing environment) all the 50 strains tested were able to grow in the presence of bile salts concentrations as high as those presented in the small intestine. Bile salt degradation ability was also found to be independent of the origin of the strains. Lianou et al. (2006) reported variation in the response to heating at $55^{\circ} \mathrm{C}$ or to $\mathrm{pH} 3$ (lactic acid) among L. monocytogenes strains of various serotypes and sources, including clinical and food isolates. These authors reported that although no relation between food and clinical isolates was observed, outbreak-related isolates of serotype $4 \mathrm{~b}$ showed the highest acid resistance. In the current study, and probably due to the low number of strains of each serotype investigated, no relationship between the serotype and survival through the simulated gastric and intestinal conditions was observed. Barmpalia-Davis et al. (2008a) compared the survival of $13 \mathrm{~L}$. monocytogenes strains in a dynamic GI model. Survival to gastric acidity was demonstrated to be growth phase and strain dependent. The inactivation rates of exponential cultures were not different between pairs (outbreak origin/food associated) of food and human isolates. The highest acid susceptibility was observed for two strains of clinical origin. However, these two strains also displayed the longest lag periods in death. Werbrouck et al. (2008) did not find correlation between origin (clinical and meat) and survival of L. monocytogenes serotype $4 \mathrm{~b}$ in synthetic gastric fluid.

To our knowledge, the differences in the survival through simulated GI stress conditions between food and clinical isolates observed in the present study-clinical isolates were more resistant than food isolates-have not been previously described. These results corroborate previous suggestion (Dykes and Moorhead, 2000) of the importance of acid tolerance in the infection process. However, for the strains investigated, Werbrouck et al. (2008) found differences in the survival capacity in gastric fluid and in vivo virulence potential demonstrating the difficulty of determining the virulence capacity of L. monocytogenes strains. Moreover, Garner et al. (2006) suggested that virulence-associated characteristics of L. monocytogenes might be affected by food-specific properties. This highlights the importance of molecular and phenotypic characterization and comparison of strains of different origins to provide a greater insight into the virulence potential of L. monocytogenes.

It is important to point out that the results of the present study were obtained under static conditions, not considering the gradual acidification that occurs in the stomach during digestion, and in the absence of a food matrix. Peterson et al. (2007) demonstrated that for L. monocytogenes F2365 resistance to synthetic gastric fluid was higher when growth was performed on deli turkey meat than in brain-heart infusion. Barmpalia-Davis et al. (2008b) reported that during the gradual $\mathrm{pH}$ decrease in a dynamic simulation of the stomach conditions, L. monocytogenes on bologna and salami slices survived during the initial stages and a high cell number attained the simulated small intestine. The same authors reported protective effects of fat against gastric destruction of the pathogen (Barmpalia-Davis et al., 2009). Samara et al. (2009) reported that when exposed to organic acids during the decontamination of lettuce, the resistance of L. monocytogenes to a subsequent exposure to the simulated gastric fluid did not increase. In fact decontamination with lactic acid increased the sensibility of the cells to the simulated conditions.

Despite the limitations attributed to the model of the GI conditions used in this work, the generated information would be a valuable contribution for further studies in the context of microbiological risk assessments. Further, selection of strains for further studies concerning virulence of food isolates of L. monocytogenes will take advantage of these results.

\section{Conclusions}

Following the ingestion of contaminated food by a mammalian host, L. monocytogenes have the ability to survive through the acid environment of the stomach, the secretion of proteolytic enzymes, and the inhibitory activity of bile salts. During this study, the conditions of the GI tract were simulated, and the survival of different isolates of L. monocytogenes was evaluated. This simulation did not take into account the gradual acidification that normally occurs in the stomach upon ingestion of a meal, nor the protective effect of food against the lethal action of acid or bile salts. However, the ability of L. monocytogenes to survive through highly adverse conditions was demonstrated and was shown to be strain dependent; clinical isolates were more resistant to the tested conditions. 


\section{Acknowledgments}

This work was supported by CT project-2006-016264Truefood. Traditional United Europe Food, and by FCT projectPTDC/AGR-ALI/64662/2006-Listeria monocytogenes in foods: contributing data for risk assessment.

\section{Disclosure Statement}

No competing financial interests exist.

\section{References}

Almeida G, Gibbs P, Hogg T, and Teixeira P. Listeriosis in Portugal: an existing but under reported infection. BMC Infect Dis 2006;6:152-156.

Avery SM and Buncic S. Differences in pathogenicity for chick embryos and growth kinetics at $37^{\circ} \mathrm{C}$ between clinical and meat isolates of Listeria monocytogenes previously stored at $4^{\circ} \mathrm{C}$. Int J Food Microbiol 1997;34:319-327.

Barmpalia-Davis IM, Geornaras I, Kendall PA, and Sofos JN. Differences in survival among 13 Listeria monocytogenes strains in a dynamic model of the stomach and small intestine. Appl Environ Microbiol 2008a;74:5563-5567.

Barmpalia-Davis IM, Geornaras I, Kendall PA, and Sofos JN. Survival of Listeria monocytogenes in a simulated dynamic gastrointestinal model during storage of inoculated bologna and salami slices in vacuum packages. J Food Prot 2008b;71:2014-2023.

Barmpalia-Davis IM, Geornaras I, Kendall PA, and Sofos JN. Effect of fat content on survival of Listeria monocytogenes during simulated digestion of inoculated beef frankfurters stored at $7^{\circ} \mathrm{C}$. Food Microbiol 2009;26:483-490.

Begley M, Gahan CGM, and Hill C. Bile stress response in Listeria monocytogenes LO28: adaptation, cross-protection, and identification of genetic loci involved in bile resistance. Appl Environ Microbiol 2002;68:6005-6012.

Bell C and Kyriakides A. Listeria: A Practical Approach to the Organism and Its Control in Foods. London: Blackwell Publishing, 2005.

Branen J and Davidson PM. Activity of hydrolysed lactoferrin against foodborne pathogenic bacteria in growth media: the effect of EDTA. Lett Appl Microbiol 2000;30:233-237.

Brett M, Short P, and McLauchlin J. A small outbreak of listeriosis associated with smoked mussels. Int J Food Microbiol 1998;43:223-229.

Brown $\mathrm{M}$ and Booth I. Acidulants and low pH. In: Food Preservatives. Russel NJ and Gould GW (eds.). Glasgow: Blackie and Son, 1991, pp. 22-43.

Dykes GA and Moorhead SM. Survival of osmotic and acid stress by Listeria monocytogenes strains of clinical or meat origin. Int J Food Microbiol 2000;56:161-166.

Gahan CGM and Hill C. Gastrointestinal phase of Listeria monocytogenes infection. J Appl Microbiol 2005;98:1345-1353.

Garner MR, James KE, Callahan MC, Wiedmann M, and Boor KJ. Exposure to salt and organic acids increases the ability of Listeria monocytogenes to invade Caco-2 cells but decreases its ability to survive gastric stress. Appl Environ Microbiol 2006; 72:5384-5395.

King T, Ferenci T, and Szabo EA. The effect of growth atmosphere on the ability of Listeria monocytogenes to survive exposure to acid, proteolytic enzymes and bile salts. Int J Food Microbiol 2003;84:133-143.

Lianou A, Stopforth JD, Yoon Y, et al. Growth and stress resistance variation in culture broth among Listeria monocytogenes strains of various serotypes and origins. J Food Prot 2006;69:2640-2647.
Madureira AR, Pereira CI, Truszkowska K, Gomes AM, Pintado $\mathrm{ME}$, and Malcata FX. Survival of probiotic bacteria in whey cheese vector submitted to environmental conditions prevailing in the gastrointestinal tract. Int Dairy J 2005;15:921-927.

Mahoney $\mathrm{M}$ and Henriksson A. The effect of processed meat and meat starter cultures on gastrointestinal colonization and virulence of Listeria monocytogenes in mice. Int J Food Microbiol 2003;84:255-261.

McLauchlin J. The relationship between Listeria and listeriosis. Food Control 1996;7:187-193.

McLauchlin J, Mitchell RT, Smerdon WJ, and Jewell K. Listeria monocytogenes and listeriosis: a review of hazard characterisation for use in microbiological risk assessment of foods. Int J Food Microbiol 2004;92:15-33.

Miles AA and Misra SS. The estimation of the bactericidal power of blood. J Hyg 1938;38:732-749.

Miller F, Brandão T, Teixeira P, and Silva CML. Recovery of heatinjured Listeria innocua. Int J Food Microbiol 2006;12:261-265.

Miller DC and Czuprynski CJ. Passive immunization with convalescent serum, or oral immunization with formalin-killed organisms, does not protect mice against gastrointestinal challenge with Listeria monocytogenes. Comp Immunol Microbiol 2002;25:69-75.

Murray EGD, Webb RA, and Swann MBR. A disease of rabbits characterised by a large mononuclear leucocytosis, caused by a hitherto undescribed bacillus Bacterium monocytogenes (n.sp.). J Path Bacteriol 1926;29:407-439.

Nørrung B. Microbiological criteria for Listeria monocytogenes in foods under special consideration of risk assessment approaches. Int J Food Microbiol 2000;62:217-221.

Nyachuba D and Donnelly C. Sublethal injury, pathogen virulence and adaptation. In: Understanding Pathogen Behavior, chapter 7. Griffiths M (ed.). Cambridge, UK: Woodhead Publishing Ltd., 2005, pp. 152-198.

Olier M, Rousseaux S, Piveteau P, Lemaître J, Rousset A, and Guzzo J. Screening of glutamate decarboxylase activity and bile salt resistance of human asymptomatic carriage, clinical, food, and environmental isolates of Listeria monocytogenes. Int I Food Microbiol 2004;93:87-99.

Peterson LD, Faith NG, and Czuprynski CJ. Resistance of Listeria monocytogenes F2365 cells to synthetic gastric fluid is greater following growth on ready-to-eat deli turkey meat than in brain heart infusion broth. I Food Prot 2007;70:2589-2595.

Ribeiro MH, Manha S, and Brito L. The effects of salt and $\mathrm{pH}$ stress on the growth rates of persistent strains of Listeria monocytogenes collected from specific ecological niches. Food Res Int 2006;39:816-822.

Samara A and Koutsoumanis KP. Effect of treating lettuce surfaces with acidulants on the behaviour of Listeria monocytogenes during storage at 5 and $20^{\circ} \mathrm{C}$ and subsequent exposure to simulated gastric fluid. Int J Food Microbiol 2009;129:1-7.

Sleator RD, Clifford T, and Hill C. Gut osmolarity: a key environmental cue initiating the gastrointestinal phase of Listeria monocytogenes infection? Med Hypotheses 2007;69: 1090-1092.

Soultos N, Abrahim A, Papageorgiou K, and Steris V. Incidence of Listeria spp. in fish and environment of fish markets in northern Greece. Food Control 2007;18:554-557.

Uyttendaele M, Rajkovic A, Van Houteghem N, Nico B, Olivier T, Johan D, and Frank D. Multi-method approach indicates no presence of sub-lethally injured Listeria monocytogenes cells after mild heat treatment. Int J Food Microbiol 2008;123:262268. 
Vialette M, Pinon A, Chasseignaux E, and Lange M. Growths kinetics comparison of clinical and seafood Listeria monocytogenes isolates in acid and osmotic environment. Int J Food Microbiol 2003;82:121-131.

Werbrouck H, Botteldoorn N, Ceelen L, Decostere A, Uyttendaele M, Herman L, and Van Coillie E. Characterization of virulence properties of Listeria monocytogenes serotype $4 \mathrm{~b}$ strains of different origins. Zoonoses Public Health 2008;55: 242-248.
Address correspondence to: Paula Teixeira, Ph.D. $\mathrm{CBQF} /$ Escola Superior de Biotecnologia Universidade Católica Portuguesa Rua Dr. António Bernardino de Almeida 4200-072 Porto Portugal

E-mail: pcteixeira@esb.ucp.pt 